\title{
İmam Şafii divanında ilim
}

Orhan OĞUZ¹

\section{Serkut Mustafa DABBAGH²}

\begin{abstract}
APA: Oğuz, O.; Dabbagh, S. M. (2019). İmam Şafii divanında ilim. RumeliDE Dil ve Edebiyat Araştırmaları Dergisi, (14), 215-223. DOI: 10.29000/rumelide.541013
\end{abstract}

\section{$\ddot{\mathbf{O} z}$}

Günümüz dünyasında eğitim ve öğretim ile ilgili sürekli yeni teoriler ortaya çlkmaktadır. Bu teknikleri incelediğimizde şu husus ortaya çımaktadır: Eğitim ve öğretim ile ilgili teknikler bir önceki tekniğinin eleştirisi üzerine gelişmiştir. İlimde eleştirinin yerini asla inkâr edemeyiz. Çünkü eleştiri ilimlerin ilerlemesini sağlamıştır ve sağlamaya da devam edecektir. Ancak eleştirinin yanına önceki âlimlerin tecrübelerinin de göz önüne alınması elde edilecek faydayı artıracaktır. Önceki âlimlerin tecrübeleri konusunda bu çalışmada İmam Şafii’nin ilimle ilgili beyitleri incelenecektir. İmam Şafii İslam dünyasındaki dört hak mezhepten birinin kurucusudur. O genelde bu özelliği ile bilinir. Fakat Hadis, Fıkıh gibi dini ilimlerin yanında Arapça ve Edebiyat ile de meşgul olmuştur. Şiir yazmış ama bu şiirlerini bir kitapta toplamamıştır. Onun şiirleri biyografi kitaplarında yer almıştır. Bu şiirleri Abdurrahman b. el-Mustavî ve Muhammed İbrahim Selim derleyerek ayrı iki kitap halinde neşretmiştir. Bu çalışmada İmam Şafii’nin şiirlerini incelemekte iki husus hedeflenmiştir. Birincisi İmam Şafii’nin edebiyatçı yönünü tanıtmak. Çünkü yukarıda da bahsedildiği gibi onun sadece tek bir yönü bilinmektedir. İkincisi divanında geçen ilimle ilgili beyitleri günümüz eğitim anlayışıla karşllaştırmak. Böylece günümüz modern eğitim anlayışılla, önceki âlimlerin tecrübelerinin bir araya getirilme zemini araştırılacaktır. Araştırma iki bölüm ve sonuçtan oluşmaktadır. Giriş bölümünde İmam Şafii'nin hayatı ile ilgili bilgiler verilmiştir. Giriş bölümünden sonra İmam Şafii’nin divanında ilimle ilgili beyitleri açıklanmıştır. Bunlar: İlmin önemi, ilmin faydası, ilim için en uygun yaş, ilmin kaynağı, yazmanın (not almanın önemi), ilimde orjinallik nakilciliğe tepki ve ezber için yapılması gerekenler.

Anahtar kelimeler: İmam Şafii, bilim, şiir, edebiyat, Arapça.

\section{The knowledge in Diwan's Şafii}

\begin{abstract}
In today's world, new theories are emerging continuous about education and training. When we examine these techniques, the following issue arises: Techniques related to education and training have evolved on the criticism of the previous technique. We can never deny the place of criticism in science. Because criticism has made progress in science and will continue to provide. However, taking into account the experiences of the previous scholars in the name of criticism will increase the benefits. In this study about the experiences of the previous scholars, will be examined the poems of Imam Shafii. Imam Shafii is the founder of four rights sects in the Islamic World. He is known
\end{abstract}

1 Dr. Öğr. Üyesi, Karamanoğlu Mehmetbey Üniversitesi, Edebiyat Fakültesi, Mütercim Tercümanlık Bölümü, (Karaman, Türkiye), arapcadersi@hotmail.com, ORCID ID: 0000-0001-5467-3671 [Makale kaylt tarihi: 30.01.2019-kabul tarihi:13.03.2019; DOI: 10.29000/rumelide. 541013]

2 Dr. Öğgr. Üye., Karamanoğlu Mehmetbey Üniversitesi, Edebiyat Fakültesi, Mütercim Tercümanlık Bölümü, (Karaman, Türkiye), smustafa@kmu.edu.tr, ORCID ID: 0000-0002-8389-9749 


\begin{abstract}
generally by this property. But, he was also engaged in Arabic and Literature. He wrote poems but did not collect these poems in a book. His poems have been featured in biography books. Abdurrahman b. al-Mustavi and Muhammad Ibrahim Selim compiled these poems and published them into two books. In this study, two aspects of Imam Shafii's poems are studied. First, to introduce the literary aspect of Imam Shafii. The second is to compare the couplets related to the knowledge in the divan with today's education concept. The research consists of two chapters and results. In the introduction, information about the life of Imam Shafi'i given. After the introduction, the verses about the science of Imam Shafii explained. These are the importance of science, benefit of science, best age for science, source of knowledge, importance of writing, originality in science, reaction to transport and things to do for memorization
\end{abstract}

Key words: Imam Shafii, science, poetry, literature, Arabic.

\title{
Giriş
}

İmam Şafii'nin tam ismi Ebu Abdullah Muhammed b. İdris b. Abbas b. Osman'dır (ez-Zehebî, 2006: 8/236). Kendisine el-Kureşî, el-Matlabî, Ebu Abdullah künyeleri de verilmiştir. Filistin Gazze'de dünyaya gelen Şafii daha sonra oradan Mekke'ye intikal etmiştir (es-Safedi, 2000: 2/121). Çalışmalarını bir süre Mekke'de yürüttükten sonra Kahire'ye geçmiş, hicri 767 miladi 820 yllında burada vefat etmiştir. Kabri Kahire'de bulunmaktadır (el-Mustavi, 2005: 9). İmam Şafii Mekke müftüsü Müslim b. Halid ez-Zencî, Davud b. Abdurrahman el-Attar, amcası Muhammed b. Ali b. Şafî, Süfyan b. Uyeyne, Abdurrahman b. Ebu Bekr el-Mekkî, Said b. Salim, Fudayl b. Iyad gibi âlimlerden ders almıştır (ezZehebî, 2006: 8/236). İmam Şafii, Arapça, Şiir, Eyyamu'l-Arab konularında temayüz etmiş bir kimsedir. Daha sonra Fıkıh ve Hadisle ilgilenmiştir. Daha çok fıkıh alanında eserler veren Şafii’nin en önemli eseri el-Umm adlı kitabıdır. Yedi cilt olan bu kitabı el-Buveyti bir araya getirmiştir. er-Rabi b. Süleyman da kitabı konulara bölmüştür (el-Mustavi, 2005: 9). Bunun dişında el-Musned, er-Risale, Muhtelefu'lHadis, Edebu'l-Gâdî, Fadâilu Kureyş, es-Sunen (el-Mustavi, 2005: 10) onun diğer eserleridir. Geçmişte ve günümüzde İmam Şafii’nin İslam hukuku ile ilgili yönü bilinir. O aynı zamanda iyi bir şairdir. Ama şiirlerini kendisi bir divanda toplamamıştır. Onun şiirleri, o asırdaki alimlerin biyografilerini içeren kitaplarda dağınık bir şekilde günümüze kadar gelmiştir (el-Mustavi, 2005: 11). Bu şiirler Abdurrahman b. el-Mustavî ve Muhammed İbrahim Selim tarafından derlenerek ayrı iki kitap halinde neşredilmiştir.

Şiirlerinde çok farklı konulara değinmiştir. Bunlar, dua, dostların ayrılışı, takdir edilmeme, er kişilerin heybeti, ideal arkadaş vb. başlıklarda görüldüğü gibi daha çok ahlaki ve öğüt verici bilgilerdir. ìlim ile ilgili bölümler de divanında sıkça görülen konulardır. Çünkü ilim günümüzde olduğu gibi geçmişte de hem ferdin hem toplumun sürekli peşinde olduğu bir özelliktir. Bu araştırmamızda İmam Şafii’nin ilimle ilgili olan beyitleri günümüz ilim anlayışıyla karşılaştırmalı olarak incelenmiş, ortak noktaları ve ayrıldıkları noktaların olup olmadığı ortaya konulmuştur. İlimle ilgili görüşleri dokuz başlık altında toplanmıştır. Bu başlıklar şunlardır: İlmin önemi, ilmin faydası, ilim için en uygun yaş, ilmin kaynağı, yazmanın (not almanın önemi), her an ilimle meşgul olmak, ilimde orijinallik ve nakilciliğe tepki, ezber için yapılması gerekenler.

\section{İlmin önemi}

Şurası muhakkaktır ki kişinin ilme yönelmesi için o toplumda ilme ve ilim adamına değer verilmesi gerekmektedir (ez-Zernuci, 1981: 78). Tarih boyunca ilme ve ilim adamına değer veren milletlerin yükselişe geçtiği görülmektedir. İmam Şafii, bu konuyu değişik yönleriyle incelemektedir. 
Birincisi ilim sayesinde kişinin, toplumdaki saygınlığının artacağını aşağıdaki beyitlerinde bildirmektedir ki bu günümüzde de oldukça geçerli bir olgudur. Bu durum kişiyi ilme teşvik açısından çok önemli bir olgudur.

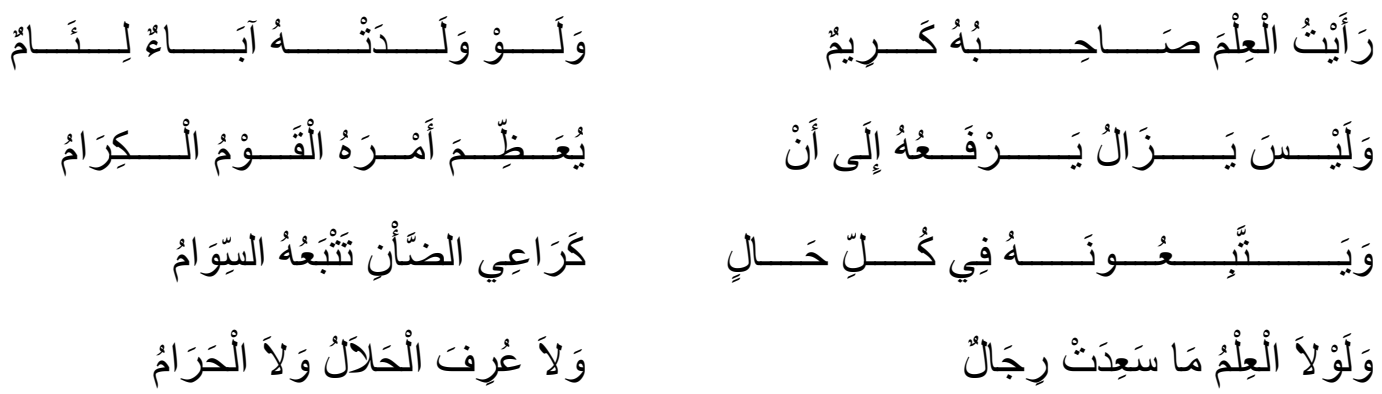

İlmi gördüm sahibi kerimdir

Doğursa da onları alçak kişiler

Onlar her daim yükselir durular

Kerim insanlar yüceltene kadar

Her daim takip ederler onu

Koyun çobanı gibi ki yemler onları sonunda.

Ĕger ilim olmasaydı kişi mutlu olamazdı

Ne helal bilinirdi ne de haram (el-Mustavi, 2005: 107)

İmam Şafii bu beyitlerinde bazı benzetmeler yaparak konuyu anlatmak istemiştir. Özellikle her toplumda bulunan sınıf ayrılıkları burada göze çarpmaktadır. İnsanlar soyları ile övünmektedirler. Ama bir kişi toplumun nazarında soy bakımından düşük bir aileden gelse bile ilim onu yüceltecektir. Ayrıca İmam Şafii'nin fikıh alanındaki çalışmaları buraya da yansımıştır. Bu da en son beyitteki ne helal bilinirdi ne haram sözlerinde kendini göstermektedir.

İkincisi ilim sahibi olanın toplum içerisindeki konumunu ilim sahibi olmayanla karşılaştırmaktadır. Böylece yine ilmin önemini ortaya koymaktadır. Günümüz toplumunda da kişinin hangi işi yaparsa yapsın o işte uzmanlaşmasının önemi bilinmektedir.

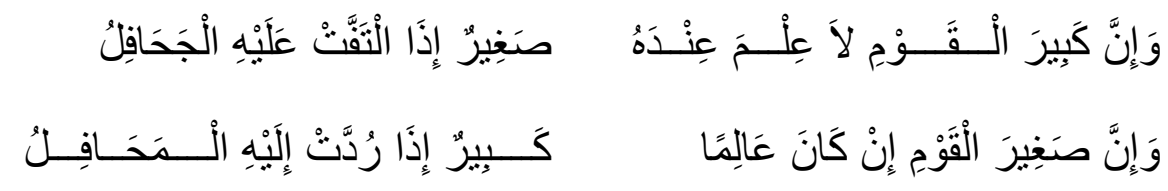

Kavmin büyüğü, olmazsa onda ilim

Küçüktür sardığında çevresini âlim.

Kavmin küçüğü şayet ise âlim

Büyüktür, verilirse ona meclis-i ilim (Selim, tsz: 118)

Bu beyitlerde de yine karşılaştırmalar görmekteyiz. Bir kavmin büyüğü ile küçüğü ilim ile konumlarını değiştirmektedirler.

Üçüncü olarak ilmin toplumun herhangi bir tabakasına has bir özellik olmadığını belirterek herkesi ilim sahibi olmaya teşvik etmektedir. 


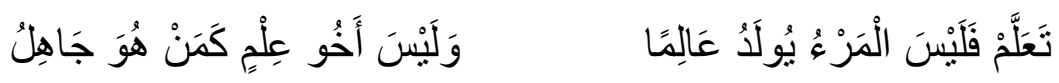

Öğren, çünkü kişi doğmaz âlim.

Değildir cahil gibi, sahib-i ilim (Selim, tsz: 118)

Son olarak da, ilim sahibini aşağıdaki beyitlerle överken cahil kalan kimseleri de ilim sahibi ile karşılaştırarak yermektedir. Böylece ilmin önemini daha belirgin bir şekilde vurgulamaktadır.

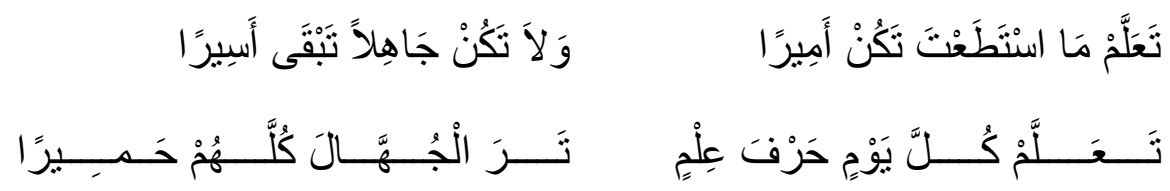

Öğren gücün yettiğince olursun emir.

Olma cahil sonra kalırsın esir.

Öğren her gün ilimden olsa da bir konu

Görürsün bütün cahilleri sanki bir hımar (el-Mustavi, 2005: 55)

Daha önceki beyitlerde de karşılaştırmalar yapılmıştı. Ama bu beyitlerinde özellikle cahilliğin kötülüğü vurgulanmıştır.

\section{İlmin faydası}

Günümüz toplumu sadece akademik başarıya yönlenmiş durumdadır. Bunda batının bilim ve teknikte ilerlemiş olmasının da önemli bir etkisi vardır. Hatta İslam dünyasının geri kalmışlığı sorunu daha çok batının teknoloji ve ekonomik gelişmişliği çerçevesinde ele alınmaktadır (Eyüpoğlu, 2004: 196).

Toplumda akademik başarının kişiye mutluluk getireceği varsayımı hakimdir. Öyle ki evde, okulda bir öğrenciden beklenen sadece bu yönde başarıya ulaşmasıdır. Akademik başarısı iyi olan öğrenciler her zaman el üstünde tutulmaktadır. İlk, orta ve lisede öğrencilere verilen karnelerde iki kısım vardır. Birinci kısmı akademik başarısını göstermekte, ikinci kısmı ise davranışları ile ilgili bilgiler vermektedir. Akademik başarısını gösteren kısım yazılı sözlü gibi verilere dayanılarak hazırlanırken, davranışları ile ilgili bölümü net verilerle hazırlanmamaktadır. Ayrıca davranışları ile ilgili bölüm aileler tarafından da dikkate alınmamaktadır. Akademik başarının üstün tutulduğunu gösteren bir anlayış da okul sanayi karşılaştırmasıdır. Aileler okul derslerine önem vermeyen erkek çocuklarını sanayiye gönderip orada çalıştırmakla tehdit etmektedirler. Halbuki çalışmak çok önemli bir erdem ve ülkenin kalkınması için gerekli olmasına rağmen toplumda böyle bir karşılaştırma hakim olmuştur.

Fakat toplumun gelişmişlik düzeyi sadece maddi unsurlarla ölçülmemelidir. Bir toplumun bilimsel alanda gösterdiği gelişme sadece bir boyuta karşllı gelmektedir. Bununla beraber sosyal kültürel ve ahlaki alanda da gelişmenin olması gerekmektedir. Çünkü bir toplum maddi ve manevi yapısı ile bir bütünlük oluşturmaktadır (Akdoğan, 2009: 13).

İmam Şafî̀ye göre ise ilim kişinin kalbindeki hidayeti, ahlakındaki güzelliği artırmalıdır. Bu durumu ilmin hidayeti başlı̆̆ını verdiği beyitlerinde şöyle dile getirmektedir.

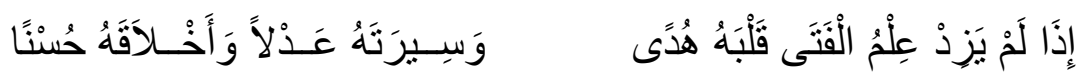




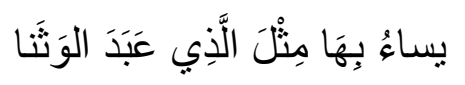

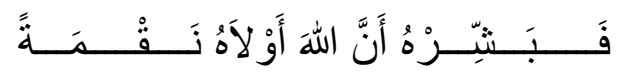

Ĕ̆er kişinin ilmi artırmazsa kalbindeki hidayeti

Ahlakındaki güzelliği, davranışındaki adaleti

Onu müjdele Allahın azap etmesinden

O daha kötüdür putlara kulluk etmekten (el-Mustavi, 2005, s. 111)

\section{İlim için en uygun yaş}

İmam Şafi'ye göre ilim elde etmek için en uygun yaş gençlik yaşıdır. Ancak gençlerin ilimden başka bir şeyle uğraşmaması gerekir. Zihninde ilimden başka bir düşüncesinin olmaması gerekir. İmam Şafiî bu fikri şu beyitlerle ifade etmiştir.
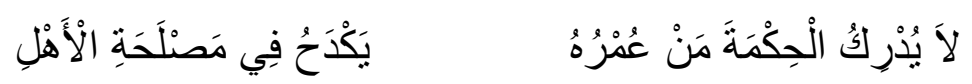

Ulaşan kavrayamaz hikmeti şu yaşa

Meşguliyeti varsa eğer ehlinin işleri onda (Selim, tsz: 118)
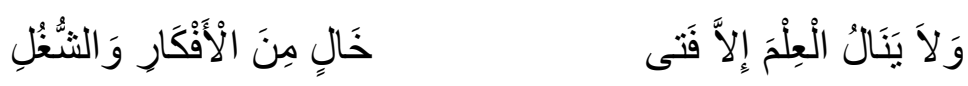

İlmi ise elde edebilir ancak gençler

Yoksa eğer onlarda düşünceler ve işler (Selim, tsz: 118)

Bu konuya günümüz yabancı dil öğretim anlayışını örnek olarak verirsek, dil öğretimine erken yaşta başlanması gerektiği görüşü hakimdir. Hatta küçük yaşta başlayan yabancı dil öğretimi, çocuğun anadil ediniminde herhangi bir sekteye uğramasına sebep olmayacağı aksine anadil öğrenimine de faydası olacağı belirtilmektedir (Kara, 2004, s. 305). Çünkü çocukların zihni daha berraktır. Öğrenmeye daha müsaittir. Bunun için yabancı dile başlama yaşı ilkokul seviyesine inmiştir.

Ayrıca ilköğretimden sonra kişinin ilgi ve becerisine göre alanların belirlenmesi ve yönlendirilmesi çalışmaları yapılmaktadır. Bu yönlendirmelerin amacı öğrencinin yetenek, ilgi ve kişilik özelliklerini tanımalarına ve farkında olmalarına yardımcı olmaktır (Akan, Çelik, \& Diş, 2014: 61). Her ne kadar bu yönlendirmelerin istenilen boyutta olduğu iddia edilemese bile başlangıç açısından iyi bir fikir olduğu ortadadır.

Şunu da belirtmek gerekir ki İmam Şafii’nin ilim için en uygun yaş olarak gençlik çağını göstermesi ile günümüzde ise ilkokuldan sonra öğrencinin yeteneğine göre alanlara yönlendirilmesi arasında bir zıtllk söz konusu değildir. İmam Şafii bilindiği gibi İslam hukuku alimidir. İslam’a göre kişi ergenlik çağına girdiğinde sorumluluk çağına başlamış olmaktadır. Bu da günümüzdeki ortaokul yıllarıdır. Dolayısıyla her iki görüşte bir uygunluk vardır.

\section{İlmin kaynağı}

Klasik düşüncede ilmin kaynağı üçtür. Bunlar akıl, beş duyu ve doğru haberdir. (Atılgan, 2013: 196). İnsan için iki türlü ilimden bahsedilmektedir. Bunlardan ilki insanın çalışma ve gayretinin bir sonucu olarak kazandığı kesbi ilim, diğeri de herhangi bir gayreti olmadan yaratılıştan gelen ıztırarı ilimdir ki 
buna içgüdü adı da verilmektedir (Atılgan, 2013: 201). İmam Şafii ilmin kaynağını ilme ancak şu altı şeyle ulaşabilirsin adını verdiği şu beyitlerinde açıklamıştır.
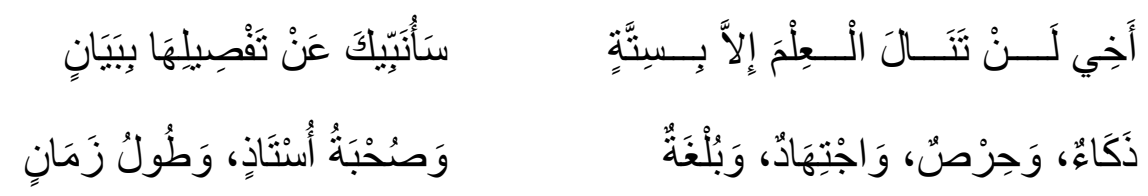

Kardeşim ilmi elde edersin ancak dokuz şeyle

Onları sana anlatıp genişçe edeceğim beyan

Zeka, hırs, gayret ve yeterlilikle

Hocayla beraberlik ve bir de uzun zaman (el-Mustavi, 2005: 122)

\section{Yazmanın (not almanın önemi)}

İnsanlık yazıyla ilk defa M.Ö. 3200 yıllarında tanışmıştır. Güney Mezopotamya'da yaşayan Sümerliler ilk kez çivi yazısını icat etmişler (Kılıç, 2009: 124) ve bu bilim tarihinde çok önemli bir yeri işgal etmiştir. Fakat özellikle edebiyat bazı toplumlarda sözlü edebiyat olarak devam etmiştir.

İslam öncesi Arap edebiyatı da sözlü edebiyattı. Her şairin yetiştirdiği bir öğrencisi olurdu. Bu öğrenci hocasının şiirlerini sonraki nesillere aktarırdı (Demirayak, 2012: 96). İslam dini ile birlikte toplumda bir takım değişiklikler olmuştur. İnançta, ibadetlerde, toplum hayatında bir takım düzenlemeler olduğu gibi bilim ve edebiyatta da değişiklikler meydana gelmiştir. Kuranı Kerim’in yazılması gayretlerinin bir sonucu olarak yazıya ilgi artarken Kur'ân'ın dil ve üslubundaki incelikleri ortaya koyma yönündeki çabalar da belagat gibi dil bilimlerinin doğuşuna zemin hazırlamıştır (Cengiz 2018: 102). Yazının önemini İmam Şafii ilim bir avdır başlı̆̆ını verdiği şu beyitlerinde dile getirmiştir.
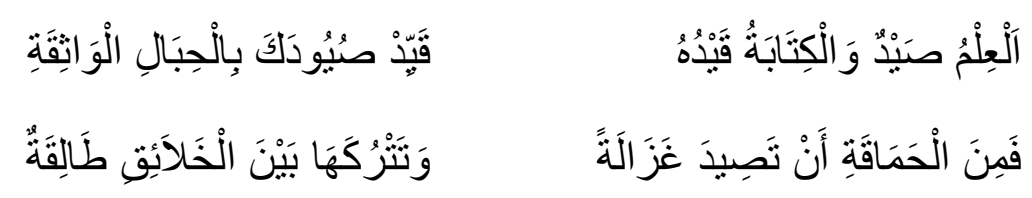

İlim bir avdır. Bağıdır onun yazı.

Bağla sen sağlam iplerle avlarını.

Ne ahmaklıktır bir ceylan avlasan

Sonra kalsa kainatta bağsız bıraksan (el-Mustavi, 2005: 84)

Sözlü edebiyat döneminin yaşandığı toplumlar belli bir süre sonra yazılı edebiyata geçmişlerdir. Burada sözlü edebiyatın tamamen yanlış olduğunu da söylemek mümkün değildir. Sözlü edebiyatın da birtakım artıları vardır. Örnek olarak Cahiliye dönemi Arap edebiyatı sözlü edebiyattı. Fakat bu durum bir şairin şiirini herkesin rivayet ettiği anlamına gelmemektedir. Her şairin bir ravisi yani şiirini sonraki nesillere aktaran bir kişi vardır. Şiir ravisi de aynı zamanda şairdir. Bu durum bir usta çırak ilişkisi içerisinde devam etmiştir (Demirayak, 2012: 96). Fakat belli bir süre sonra yazılı edebiyata geçmezse bu zincir kırılıp edebiyata zarar vermektedir. Abbasiler döneminde Cahiliye dönemi şiirleri derlenerek yazılı edebiyata geçilmiştir. Günümüzde de not almanın ve öğrenilen bilgilerin kaydedilmesinin önemi bilinmektedir. 


\section{Her an ilimle meşgul olmak}

İlim ve sanatla uğraşan kişilerin sürekli olarak kendi sahasında araştırmalar yapması ve kendisini alanından koparmaması gerekmektedir.

İlim adamı olabilmek için zekanın yeterli olabileceği yanlış bir inanıştır. Zeka elbette çok önemlidir. Ama tek başına yeterli değildir. Bunun yanında çalışkanlık, dikkati yoğunlaştırabilme gücü, uzun araştırmalar sonucunda kişinin hipotezinin çürüyebilmesi gibi bir zorluk karşısında bile yılmamak ve sebat edebilmek de gerekli olan unsurlardır (Medawar \& Arık, 1994, s. 10). Bütün bu sayılanlar kişinin her an ilimle meşgul olmasında kendini göstermektedir. İmam Şafii bu durumu şu şekilde ifade etmiştir:

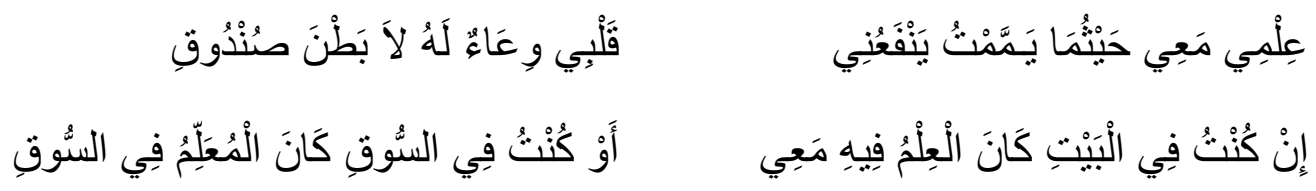

Nereye yönelsem ilim benimledir. Bana fayda verir.

Kalbim onun kabıdır. Sandığın dibi değil.

Eğer olsam ben evde ilim de olur benimle

Ya da sokakta olsam, ilim de sokakta benimle (Selim, tsz: 88)

Aynı konu ilimle beraber başlı̆̆ını verdiği şu beyitlerinde de görülmektedir.

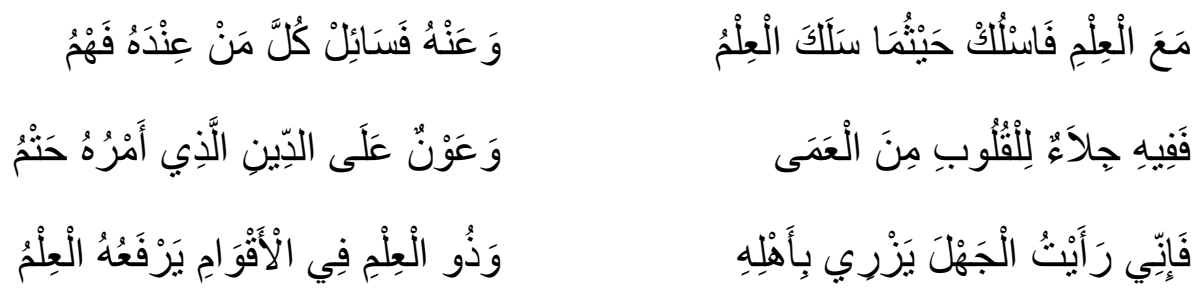

Yürü ilimle birlikte ilim seni nereye götürse.

Onu sor anlayışı olan herkese.

Onda vardır kalbin körlüğüne karşı bir cila

Ve yardır dinine yardım, buyruğu kesin olana.

Ben cehaleti gördüm ki küçük düşürür ehlini

İlim sahibi ise kavmi içinde yükseltir onu ilmi (el-Mustavi, 2005: 105)

\section{İlimde orjinallik nakilciliğe tepki}

Nakilcilik, bilimde çok eleştirilen bir kavramdır. Özellikle İslam dünyasında on altıncı yüzyıldan itibaren nakilci bilim anlayışı hakim olmuş, analiz ve senteze dayalı bilim anlayışından uzaklaşıldığı görüşü hakimdir (Kurt, 2008: 61). İmam Şafiî nakilci anlayışın zararını şeytanın vesvesesi diyerek yermektedir.

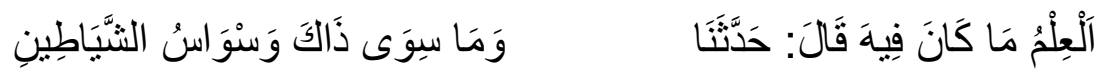

İlim içerisinde diyorsa ki haber verdi bana

Şeytanın bir vesvesesidir ya da benzeri bir mana (el-Mustavi, 2005: 118) 


\section{Ezber için yapılması gereken}

İmam Şafiye göre ilmin faydası ile aynı kategoride ele alınacak bir husus da ezber kabiliyetinin geliştirilmesi ile ilgilidir. Günümüz eğitim sistemi ezberci sistemden daha çok anlamaya dayalı bir sistemdir. Fakat ezberin eğitimde tamamen kaldırılması mümkün değildir. Çünkü matematik, fizik, kimya formülleri ezbere dayandığı gibi dini alanda surelerin ezberlenmesi ve hafızlık müessesesi ezbere dayanmaktadır. İmam Şafi ezber kabiliyetinin geliştirilmesi için günahlardan uzak durmanın gerekliğine işaret ederek ilim ve ahlak arasında ezber bakımından da bir bağ kurmuştur.

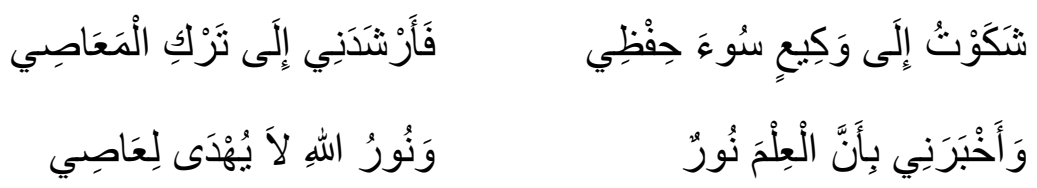

Şikayette bulundum Veki’ye ezberim kötü diye

Bana yol gösterdi günahları terk et diye

Söyledi bana ilim bir nurdur diye

Allah'in nurudur o yol göstermez asiye. (el-Mustavi, 2005: 70)

\section{Sonuc}

İmam Şafii’nin ilim ile ilgili beyitlerinde günümüz için de geçerli çok önemli ilkeler ortaya çıkmaktadır. Bunlar:

1. Toplumlar ilimle ilerlemişlerdir. Bu yüzden ilim ve ilim adamının toplumda saygın bir yeri vardır.

2. İlme yeteneği olanlar küçük yaşta tespit edilmeli ve bu yolda ilerlemesi sağlanmalıdır. İlimle uğraşan kimse zihnini meşgul edecek şeylerden uzak durmalıdır.

3. İlmi elde etmek için sabır, çok çalışma önemlidir. Ayrıca not tutma tekniklerinin iyi öğrenilmesi gereklidir.

4. İlimde her zaman orijinallik olmalıdır. Sadece geçmişte yapılan şeylerin nakledilmesi ilmi değildir.

5. İlimde sadece ezberciliğe gidilmemeli ama ezberin de önemi ihmal edilmemelidir.

6. İlim tek başına insan ve toplumların gelişmesi için yeterli değildir. İlimle birlikte ahlak eğitimi de önemlidir.

\section{Kaynakça}

Akan, D; Çelik, Z, \& Diş, O. (2014). «ilköğretimde Yöneltme Yönergesi Uygulamalarının Öğretmen Görüşlerine Göre Değerlendirilmesi .» Ekev Akedemi Dergisi.

Akdoğan, A. (2009). «Sosyal Gelişmenin İki Dinamiği Bilim ve Ahlak.» Dinbilimleri Akademik Araştırma Dergisi: 11-44.

Atılgan, Y. K. (2013). «İslam Düşüncesinde İlmin Kaynağı İmkanı ve Sınırları.» Muş Alparslan Üniversitesi Sosyal Bilimler Dergisi: 191-214.

Cengiz, E. (2018). "Endülüs Tefsir Anlayışında Belağat İlminin Yeri", Şehr-i Nuh Uluslararası Multidisipliner Çalışmalar Kongresi, Ed. Gültekin Gürçay, İksad Yayınevi, Cizre-Şırnak.

Demirayak, K. (2012). Arap Edebiyatı Tarihi I. Erzurum: Fenomen Yayınları.

el-Mustavi, A. (2005). Divanu İmam eş-Şafii. Beyrut-Lübnan: Dauru'l-Marife. 
es-Safedi, S. H. b. E. b. A. (200). el-Vafi bi'l-Vefiyat. Beyrut.

Eyüpoğlu, O. (2004) «İslam Dünyasının Geri Kalmışlık Sorununa Kurtuluşçu Yaklaşımlar.» Ekev Akademi Dergisi: 195-218.

ez-Zehebî, Ş. E. A. M. b. A. b. O. (2006). Siyeru Alâmi'n-Nubela. Kahire: Daru'l-Hadis.

ez-Zernuci. (1981). Talimu'l-Muteallim. Beyrut: el-Mektebu'l-İslami.

Kara, Ş. (2004) «Anadil Edinimi ve Erken Yaşta Yabancı Dil Öğretimi.» Uludağ Üniversitesi Eğitim Fakültesi Dergisi.

Kılıç, Y. (2009) «Eski Ön Asya Toplumları Arasında Yazı ve Dil Etkileşimi.» Pamukkale Üniversitesi Sosyal Bilimler Enstitüsü: 122-151.

Kurt, A. (2008). «İslam ve Geri Kalmışlık Sorunu.» Uludağ Üniversitesi İlahiyat Fakültesi Dergisi: 3572.

Medawar, P.M., ve Çev: Arık, N. (1994). Genç Bilim Adamına Öğütler. Ankara: Tübitak.

Selim, M. İ. (tsz). Divanu'l-İmam eş-Şafii. Kahire: Mektebetu İbn Sina. 